\title{
Tumor suppressor genes and their underlying interactions in paclitaxel resistance in cancer therapy
}

Jia-Hui Xu ${ }^{1,2}$, Shi-Lian Hu ${ }^{1,2}$, Guo-Dong Shen ${ }^{1,2^{*}}$ and Gan Shen ${ }^{1,2^{*}}$

\begin{abstract}
Objectives: Paclitaxel (PTX) is frequently used in the clinical treatment of solid tumors. But the PTX-resistance is a great obstacle in cancer treatment. Exploration of the mechanisms of drug resistance suggests that tumor suppressor genes (TSGs) play a key role in the response of chemotherapeutic drugs. TSGs, a set of genes that are often inactivated in cancers, can regulate various biological processes. In this study, an overview of the contribution of TSGs to PTX resistance and their underlying relationship in cancers are reported by using GeneMANIA, a web-based tool for gene/protein function prediction.
\end{abstract}

Methods: Using PubMed online database and Google web site, the terms "paclitaxel resistance" or "taxol resistance" or "drug resistance" or "chemotherapy resistance", and "cancer" or "carcinoma", and "tumor suppressor genes" or "TSGs" or "negative regulated protein" or "antioncogenes" were searched and analyzed. GeneMANIA data base was used to predict gene/protein interactions and functions.

Results: We identified 22 TSGs involved in PTX resistance, including BRCA1, TP53, PTEN, APC, CDKN1A, CDKN2A, HIN-1, RASSF1, YAP, ING4, PLK2, FBW7, BLU, LZTS1, REST, FADD, PDCD4, TGFBI, ING1, Bax, PinX1 and hEx. The TSGs were found to have direct and indirect relationships with each other, and thus they could contribute to PTX resistance as a group. The varied expression status and regulation function of the TSGs on cell cycle in different cancers might play an important role in PTX resistance.

Conclusion: A further understanding of the roles of tumor suppressor genes in drug resistance is an important step to overcome chemotherapy tolerance. Tumor suppressor gene therapy targets the altered genes and signaling pathways and can be a new strategy to reverse chemotherapy resistance.

Keywords: Tumor suppressor genes, Paclitaxel resistance, GeneMANIA, Molecular functions

\section{Background}

Currently, chemotherapy is the main cancer treatment modality, among which paclitaxel (PTX) is a type of cytotoxic agent and widely used in the first line treatment of lung, ovarian, breast, renal cancers and Kaposi's sarcoma [1-5]. PTX differs from conventional anti-cancer drugs because it does not affect the DNA or RNA synthesis of tumor cells or cause DNA damage, but interferes with tubulin to stabilize microtubule composition and normal

\footnotetext{
*Correspondence: gdshen@ustc.edu.cn; shenganustc@163.com ${ }^{1}$ Department of Geriatrics, Anhui Provincial Hospital affiliated to Anhui Medical University, 17 Lujiang Road, Hefei 230001, China Full list of author information is available at the end of the article
}

spindle assembly and cell division resulting in cancer cell death [6].

The clinical use of PTX leads to variable responses in different individuals, and the mechanisms of PTX resistance have not been fully elucidated. Some reports suggested that tumor suppressor genes (TSGs) should be important mediators of drug sensitivity [7-9]. Normally, these TSGs prevent abnormal cells from surviving. However, when the genes are inactivated or reduce expression, the abnormal cells grow uncontrollably, which may lead to cancer formation [10].

In this study, by the analysis of published reports and GeneMANIA network, we reviewed 21 TSGs and 1 
putative TSG that contributed to PTX resistance in cancer and provided an overview of the relationship of TSGs with PTX resistance.

\section{Overall information on the $\mathbf{2 2}$ genes related to PTX resistance in cancer}

To comprehensively collect all of the TSGs related to PTX resistance, we searched the PubMed online database and google web site, followed by an advanced search using the terms "paclitaxel response" or "paclitaxel sensitive" and "drug resistance" or "chemotherapy resistance," and "cancer" or "carcinoma," and "tumor suppressor genes" or "negative regulated protein" or "antioncogene" This search identified 22 TSGs including breast cancer 1 (BRCA1), tumor protein p53 (TP53), phosphatase and tension homolog $(P T E N)$, adenomatous polyposis coli $(A P C)$, cyclin-dependent kinase inhibitor 1A (CDKN1A), cyclin-dependent kinase inhibitor 2A (CDKN2A), high in normal-1 (HIN-1), ras association domain-containing protein 1 (RASSF1), yes-associated protein 1 (YAP), inhibitor of growth 4 (ING4), polo-like kinase 2 (PLK2), f-box and WD repeat domain containing 7 (FBW7), zinc finger MYND type containing $10(B L U)$, leucine zipper tumor suppressor 1 (LZTS1), re-1 silencing transcription factor (REST), fas-associated death domain protein $(F A D D)$, programmed cell death 4 (PDCD4), transforming growth factor- $\beta$-induced (TGFBI), inhibitor of growth 1 (ING1), bcl-2-associated X protein (Bax), PIN2/ TRF1 interacting telomerase inhibitor 1 (PinX1) and one putative tumor suppressor gene, FERM domain-containing protein $6(h E x)$, which contributed to PTX-resistance in cancer. The status, regulation manner, pathway and cancer type involved in PTX-resistance have been summarized, as shown in Table 1.

\section{BRCA1}

Tumor suppressor $B R C A 1$ is involved in several cellular functions including DNA damage repair, cell cycle checkpoint activation and transcription [11]. Several preclinical studies indicated that $B R C A 1$ might be an important determinant of response to PTX-based chemotherapy. It was shown that reconstitution of exogenous BRCA1 in the BRCA1-mutant HCC1937 breast cancer cell line resulted in enhanced sensitivity to PTX [12]. In accordance, low BRCA1 mRNA expression in ovarian cancer cell lines resulted in decreased and increased apoptotic response to PTX and platinum respectively and PTXsensitive human brain and neck squamous cell carcinoma (HNSCC) with acquired cisplatin resistance had high expression of BRCA1 $[13,14]$. In order to investigate the underlying PTX-resistance mechanisms conferred by loss of $B R C A 1$, Chabalier et al. reduced BRCA1 protein levels by using small interfering RNA (siRNA) in MCF7 breast cancer cells resulted in PTX resistance through premature inactivation of spindle checkpoint [15]. Sung et al. found that BRCA1 knockdown conferred A549 cells resistance to PTX and sensitivity to cisplatin through improving microtubule dynamics which prevented the formation of stable microtubule for caspase- 8 accumulation of PTX induced apoptosis [16]. A further study suggested that BRCA1 might represent an important mediator of the PTX stress-response dependent c-Jun N-terminal kinase/ stress-activated protein kinase (JNK/SAPK) or p38/ mitogen-activated protein kinase (p38/MAPK) pathway [17]. Taken together, these studies provided evidence that $B R C A 1$ mutation or reduced expression could predict the response to PTX-based chemotherapy. BRCA1 deficiency led to increased microtubule dynamics, impaired cell cycle checkpoint and signaling pathway which rendered less sensitivity to PTX-induced apoptosis. Here we consider that BRCA1 may become a molecular marker to predict the PTX resistance.

\section{TP53}

TP53 is one of the earliest detected tumor suppressor genes and the most frequently mutated gene in carcinoma. More than half of the TP53 mutations found in cancers lead to loss of function. Functional p53 participates in various cellular processes including cell cycle progression, cell motility, aging, apoptosis, genetic instability, DNA repair, anti-angiogenesis and cell metabolism [18]. TP53 gene mutation status has recently been shown to be correlated to PTX-based therapy and prognosis [19-21]. It was also found that an augmented concentration of intracellular p53 protein sensitized three non-small-cell lung carcinoma (NSCLC) cell lines to PTX [22]. p53 upregulated modulator of apoptosis (PUMA) is an important regulator of apoptosis and is involved in drug resistance [23]. It was demonstrated that PUMA was downregulated in PTX-resistant ovarian cell line SKOV3/PTX, and delivery of p53 into SKOV3/ PTX could upregulated the expression of PUMA and restored the apoptotic response to PTX [24]. TP53 hot spot mutation (TP53-m273) increased multidrug resistance protein 1 (MDR1, regulating efflux of PTX and doxorubicin) expression and resistance to PTX [25, 26]. In addition, studies suggested that some regulatory factors depended on p53 related pathway may mediated PTX resistance. For example, the up-regulation of inhibitor of apoptosis-stimulating protein of p53 (iASPP), a p53 suppression factor, has been found to affect PTX sensitivity in ovarian cancer by inhibiting both mitotic catastrophe and apoptosis [27]. Astrin, a protein localized with mitotic spindles at $\mathrm{M}$ phase, silencing of astrin triggered a p53-dependent apoptotic pathway and induced Hela cells sensitive to PTX [28]. 
Table 1 General overview of the 22 TSGs that contribute to PTX-resistance

\begin{tabular}{|c|c|c|c|c|c|}
\hline TSG abbreviation & Full name of the TSGs & Status & Regulation manner & $\begin{array}{l}\text { Pathway associated } \\
\text { with resistance }\end{array}$ & Type of cancer \\
\hline$B R C A 1$ & Breast cancer 1 & $\begin{array}{l}\text { Mutation }[12,17] \\
\text { Protein/mRNA level } \\
\quad[13,14]\end{array}$ & $\begin{array}{l}\text { Spindle-assembly } \\
\text { checkpoint [15] } \\
\text { Microtubule dynamic } \\
\text { [16] } \\
\text { MEKK3 activity [17] }\end{array}$ & $\begin{array}{l}\text { Apoptosis }[13,16] \\
\text { JNK/SAPK and p38/ } \\
\text { MAPK pathway [17] }\end{array}$ & $\begin{array}{l}\text { Ovarian cancer [13] } \\
\text { HNSCC [14] } \\
\text { Breast cancer }[15,17] \\
\text { NSCLC [16] }\end{array}$ \\
\hline TP53 & Tumor protein p53 & Mutation [26] & $\begin{array}{l}\text { G1 phase arrest [22] } \\
\text { Apoptosis [24] }\end{array}$ & Apoptosis [24] & $\begin{array}{l}\text { NSCLC [22] } \\
\text { Ovarian cancer }[24,26]\end{array}$ \\
\hline PTEN & $\begin{array}{l}\text { Phosphatase and ten- } \\
\text { sion homolog }\end{array}$ & Protein level $[34,35]$ & $\begin{array}{l}\text { Cyclin B1 activity [34] } \\
\text { MiR-22 [35] }\end{array}$ & $\begin{array}{l}\text { PI3 K/AKT pathway } \\
{[34,35]}\end{array}$ & $\begin{array}{l}\text { ESCC [34] } \\
\text { Colon cancer [35] }\end{array}$ \\
\hline$A P C$ & $\begin{array}{l}\text { Adenomatous polyposis } \\
\text { coli }\end{array}$ & Mutation [38] & $\begin{array}{l}\text { MDR1 [38] } \\
\text { miR-135a [40] }\end{array}$ & $\begin{array}{l}\text { Cell cycle [40], Cell } \\
\text { adhesion [41] }\end{array}$ & $\begin{array}{l}\text { Breast cancer [38] } \\
\text { NSCLC [40] }\end{array}$ \\
\hline p21/CDKN1A & $\begin{array}{l}\text { Cyclin-dependent } \\
\text { kinase inhibitor 1A }\end{array}$ & Protein level [48] & Cell cycle [48] & $\begin{array}{l}\text { Cell cycle, Apoptosis } \\
\text { [48] }\end{array}$ & Melanoma [48] \\
\hline p16/CDKN2A & $\begin{array}{l}\text { Cyclin-dependent } \\
\text { kinase inhibitor 2A }\end{array}$ & Protein level [49] & Cell cycle [49] & Cell cycle [49] & $\begin{array}{l}\text { Triple-negative breast } \\
\text { cancer [49] }\end{array}$ \\
\hline FRMD6/hEx & $\begin{array}{l}\text { FERM domain-contain- } \\
\text { ing protein } 6\end{array}$ & Protein level [8] & Cell cycle [8] & Cell cycle [8] & Breast cancer [8] \\
\hline RASSF1 & $\begin{array}{l}\text { Ras association domain- } \\
\text { containing protein } 1\end{array}$ & Methylation [54] & Cell growth [53] & Cell cycle [53] & Ovarian cancer [53] \\
\hline YAP & Yes-associated protein 1 & deletion [55] & Cell cycle [55] & Cell cycle [55] & Breast cancer [55] \\
\hline ING4 & Inhibitor of growth 4 & Protein level [56] & $\mathrm{Bcl}-2 / \mathrm{Bax}$ ratio [56] & $\begin{array}{l}\text { Apoptosis, Cell cycle } \\
\text { [56] }\end{array}$ & Lung cancer [51] \\
\hline$B A X$ & $\begin{array}{l}\text { BCL2-associated X } \\
\text { protein }\end{array}$ & mRNA level [57] & Bcl-2/Bax ratio [57] & Apoptosis [57] & Breast cancer [57] \\
\hline$H I N-1 / S C G B 3 A 1$ & High in normal-1 & Methylation [9] & Apoptosis [9] & PI3K/AKT pathway [9] & Ovarian cancer [9] \\
\hline PLK2 & Polo-like kinase 2 & Methylation [58] & $\begin{array}{l}\text { G2/M phase checkpoint } \\
\text { [58] }\end{array}$ & $\begin{array}{l}\text { Cell cycle, apoptosis } \\
\text { [58] }\end{array}$ & Ovarian cancer [58] \\
\hline LZTS1/FEZ1 & $\begin{array}{l}\text { Leucine zipper tumor } \\
\text { suppressor } 1\end{array}$ & $\begin{array}{l}\text { Protein/mRNA level } \\
{[59,60]}\end{array}$ & Cell cycle $[59,60]$ & Cell cycle $[59,60]$ & $\begin{array}{l}\text { Ovarian cancer [59] } \\
\text { Breast cancer [60] }\end{array}$ \\
\hline FBXW7/FBW7 & $\begin{array}{l}\text { F-box and WD repeat } \\
\text { domain containing } 7\end{array}$ & Mutation [62] & Ubiquitination [62] & Ubiquitination [62] & Ovarian cancer [62] \\
\hline ZMYND10/BLU & $\begin{array}{l}\text { zinc finger MYND type } \\
\text { containing } 10\end{array}$ & Methylation [63] & $\mathrm{Bcl}-2 /$ Bax ratio $[63,64]$ & $\begin{array}{l}\text { Apoptosis [63], PI3 K/ } \\
\text { Akt pathway [59, 64] }\end{array}$ & Ovarian cancer $[63,64]$ \\
\hline TGFBI & $\begin{array}{l}\text { Transforming growth } \\
\text { factor- } \beta \text {-induced }\end{array}$ & $\begin{array}{l}\text { mRNA/protein level } \\
{[66,67]}\end{array}$ & $\beta 3$ integrin $[66,67]$ & Apoptosis $[66,67]$ & $\begin{array}{l}\text { NSCLC [66] } \\
\text { Ovarian cancer [67] }\end{array}$ \\
\hline REST & $\begin{array}{l}\text { RE-1 silencing transcrip- } \\
\text { tion factor }\end{array}$ & Protein level [70] & TUBB3[70] & PI3K/AKT pathway [70] & Ovarian cancer [70] \\
\hline FADD & $\begin{array}{l}\text { Fas-associated death } \\
\text { domain protein }\end{array}$ & Phosphorylation $[72,73]$ & $\begin{array}{l}\text { Apoptosis [71] } \\
\text { Cell cycle [72] }\end{array}$ & JNK/SAPK pathway [72] & $\begin{array}{l}\text { Cervical carcinoma [71, } \\
\text { 73] } \\
\text { Prostate cancer [72] }\end{array}$ \\
\hline PDCD4 & $\begin{array}{l}\text { Programmed cell } \\
\text { death } 4\end{array}$ & $\begin{array}{l}\text { Protein/mRNA level } \\
{[74,75]}\end{array}$ & Mir-182 [74] & $\begin{array}{l}\text { Cell growth [74] } \\
\text { Cell cycle [75] }\end{array}$ & $\begin{array}{l}\text { Ovarian cancer [74] } \\
\text { Cervical carcinoma [75] }\end{array}$ \\
\hline INGI & Inhibitor of growth 1 & Protein level [76] & Apoptosis [76] & $\begin{array}{l}\text { p53-dependent path- } \\
\text { way [76] }\end{array}$ & Osteosarcoma [76] \\
\hline $\operatorname{Pin} X 1$ & $\begin{array}{l}\text { PIN2/TRF1 interacting } \\
\text { telomerase inhibitor } 1\end{array}$ & Protein level [77] & $\begin{array}{r}\text { Spindle-assembly } \\
\text { checkpoint [77] }\end{array}$ & Cell cycle [77] & Cervical carcinoma [77] \\
\hline
\end{tabular}

\section{PTEN}

PTEN, is a negative regulator of the phosphatidylinositol 3-kinase/protein kinase B (PI3k/Akt) signaling pathway. Its dysfunction mutation results in reduced dephosphorylation of phosphatidylinositol 3, 4, 5-triphosphate (PIP3), further increasing cell survival, cell migration, cell size and cell proliferation [29]. Recently, reports mainly concentrate on the role of PTEN in the response of human cancer cells to anti-cancer drugs and in multiple drug resistance (MDR) reversion [30-33]. Several reports showed that PTEN was involved in PTX resistance. Cyclin B1 plays a key role in G2/M transition. Ou et al. detected suppressing of cyclin $\mathrm{B} 1$ protein sensitized esophageal squamous cell carcinoma (ESCC) cells to 
PTX-induced apoptosis through the PTEN/PI3 k pathway [34]. Overexpression of microRNA 22 (miR-22) reversed PTX-induced cytotoxicity and this function was mediated by the regulation of PTEN levels in TP53 negative colon cell line [35]. Although PTEN is not the primary target of PTX resistance, evidences showed that its regulator can be an important target, such as suppression of cyclin B1, miR-22 or combining with inhibitor of Akt could be an attractive strategy for PTX therapy.

\section{APC}

Tumor suppressor gene $A P C$ is most commonly mutated and deleted in colorectal cancers, as well as many other epithelial cancers like breast, gastric and lung cancer. The best-known function of the APC protein is the regulation of the Wnt signaling cascade through downregulation of $\beta$-catenin can modulate cell cycle progression, however, APC has many Wnt independent roles, such as microtubule dynamic, cytoskeletal organization and cell adhesion [36, 37]. Since PTX is to interfere with microtubule protein stability, the interaction between $A P C$ and PTX has been explored. Monica et al. showed loss of $A P C$ in breast cancer cells from mouse mammary tumor virus promoter-polyoma middle T-antigen (MMTV-PyMT) mouse lead to increased expression of MDR1 after treatment with cisplatin and PTX [38]. It has been demonstrated that $A P C$ expression is regulated by a microRNA 135a (miR-135a) [39]. So it is not surprising that miR-135a is shown to be involved in PTX resistance by downregulation of APC [40]. Moreover, Ling et al. found $A P C$-deficient cancer cells defect in mitotic spindle checkpoint and in cell-cell adhesion and were more resistant to PTX $[41,42]$. Consequently, APC deficiency impairs the PTX sensitivity of cancer cells by interfering with the mitotic spindle checkpoint and decreasing apoptosis.

\section{CKIs}

Loss of cell cycle control promotes tumorigenesis, key regulators of the cell cycle are a family of serine/threonine kinases: cyclin-dependent kinases (CDKs). CDKs act at different stages of the cell cycle and are responsible for the transition from one cell cycle phase to the next [43]. Endogenous cyclin-dependent kinase inhibitors (CKIs) are negative regulators of CDKs [44]. There are two families of CKIs: the INK4 families, consisted of p16, p15, p18 and p19 which can inhibit the complex of cyclin dependent kinase 4/6 (CDK4/6) and cyclin complex activities. And the CIP/KIP families include p21, p27 and p57, regulate border CDKs [45]. Recently, evidences have showed CKIs family members involved in PTX resistance in human cancers. p21, is required to maintain the G2 arrest after DNA damage [46], the level of p21 expression has been known to play an important role in determining sensitivity of tumor cells to PTX [47], and a remarkable induction of $\mathrm{p} 21$ in A375P cells after treatment of PTX and apoptosis induction after mitotic arrest with PTX. However, PTX lightly increased the levels of p21 in A375P/Mdr cells, which exhibited strong resistance to PTX [48]. p16, mainly inhibits CDK4 activity, the loss of p16 expression reduced the response of breast cancer cells to PTX by conferring cancer stem cell properties and the tumorsphere formation was not significantly enhanced [49], those results indicated that CKIs affect PTX efficacy mainly through the cell cycle regulation.

\section{Hippo signaling pathway}

The Hippo signaling pathway, which regulates cell proliferation and apoptosis, is a highly conserved signaling pathway first discovered in Drosophila cells. It also exists in mammals and controls organ size, cell proliferation and apoptosis. The main function of Hippo signaling pathway is to phosphorylate transcriptional co-activator PDZ-binding motif (TAZ) and YAP, preventing them from entering the nucleus and promoting gene transcription which induces cell proliferation, metastasis and invasion [50]. Recent discoveries have identified the Hippo signaling pathway as a new target for cancer chemotherapy resistance [51]. For example, $h E x$, one of the Hippo upstream signal input factors, a putative tumor suppressor gene, overexpression of $h E x$ dramatically inhibited breast cancer cell proliferation and sensitivity to PTX [8]. RASSF1A, a member of the RASSF1 family, is a downstream regulator of Hippo, there are approximately $50 \%$ of ovarian tumors harbor hypermethylation of RASSF1 [52], investigations shown that overexpression of RASSFIA could increase stabilization of microtubules then restore PTX sensitivity [53]. YAP, a nuclear effector of Hippo, has been shown exist in many pathways except in Hippo, it is critical for DNA damage in breast cancer cells as well as in certain types of neuronal apoptosis [54]. It acted as a tumor suppressor in breast cancer and its silencing could induce normal breast epithelia more resistance to PTX effect on cell cycle but not apoptosis [55].

\section{Other TSGs}

In addition to the TSGs mentioned above, abnormity of ING4, Bax, HIN-1, PLK2, FBW7, LZTS1, BLU, TGFBI, REST, FADD, PDCD4, ING1 and PinX1 have also been found to mediate PTX resistance in some experiments. The protein level of ING4 was sharply decreased in PTXresistance lung cancer cells. In contrast, overexpression of ING4 protein could induce apoptosis and G2/M arrest by decreasing B-cell CLL/lymphoma 2 (Bcl-2)/ Bax ratio then reversed PTX-resistance [56]. Bax is a 
proapoptotic $B c l-2$ family member that plays a key role in induction of mitochondrial dependent apoptosis. Study found there was an increase of Bcl-2/Bax ratio in PTX-resistant breast cancer cell lines, high ratio reduced the PTX-induced apoptosis in breast cancer and ovarian cancer cells [57]. Hypermethylation downregulated the expression of $H I N-1$ and weakened the sensitivity to PTX through the PI3k/Akt pathway [9]. Hypermethylation of PLK2 reduced ovarian cancer cells sensitivity to PTX, accompanied by reduced G2-M arrest and apoptosis [58]. Low protein expression of LZTS1 showed little response in patients who received PTX-based chemotherapy in ovarian carcinoma and breast cancer patients, it was a worse prognosis patients outcome $[59,60]$, previous study by generating LZTS1 knockout mice, detected accelerate mitotic progression resistance to PTX-induced $M$ phase arrest by decreasing CDK1 activity [61], indicated cell cycle distribution may be involved in the above two human cancer. Ovarian and colon cancer cells which harbored mutant FBW7 were more resistant to PTX, functional FBW7 is required to degrade myeloid cell leukemia 1 expression by a ubiquitin ligase SKP1-cullin-1F-box complex that contains FBW7 [62]. Ovarian cancer patients with methylated $B L U$ had significantly shorter progression free survival, in vitro, $B L U$ could decrease the $\mathrm{Bcl}-2 / \mathrm{Bax}$ ratio in ovarian cancer cells when encountered with PTX [63, 64]. TGFBI acts as a tumor suppressor in lung cancer [65]. Irigoyen et al. identified a strong association between elevated TGFBI expression and the response to chemotherapy, TGFBI mediated the susceptibility of NSCLC cells to PTX and this may be the result of direct TGFBI induction of cell apoptosis through the binding of its proteolytic fragments to the $\beta 3$ integrin, the same phenomenon was proven in ovarian cancer $[66$, 67]. REST directly regulates Akt2, loss of REST leads to a de-regulation of Akt phosphorylation [68]. Tubulin beta 3 class III (TUBB3) was a biomarker of the resistance of chemotherapies [69]. Gao et al. found REST might suppress the expression of TUBB3 to sensitize ovarian cancer cells to PTX by activating the PI3k/Akt pathway [70]. Phosphorylation of FADD affected both upstream and downstream of the JNK/SAPK pathway, which was critical for sensitivity to PTX-induced apoptosis [71-73], and PDCD4 mediated PTX sensitivity through interacting mitotic exit regulation axis, upregulation of microRNA 182 (miR-182) accelerated cell cycle process and enhanced chemo-resistance of ovarian cancer cells to PTX through negatively regulating PDCD4 [74, 75]. $\mathrm{P}^{\mathrm{ING1}}{ }^{\mathrm{N}}$, one of the ING1 gene products, could enhance PTX-induced apoptosis in human osteosarcoma U2OS cells by p53-dependent pathway and its target genes p21 and Bax were increased [76]. In cervical squamous cell carcinomas, the expression of PinX1 in patients was significantly associated with the response of the combination of PTX and cisplatin chemotherapy. In vitro, knockdown of PinX1 could dramatically enhance PTX effects, whereas the augment of PinX1 levels substantially enhanced the G2 phase cells through influencing spindle assembly checkpoint [77].

Summarily, the pre-transcriptional (epigenetic/ genetic), transcriptional and post-transcriptional changes of TSGs contribute to PTX resistance in cancer, which may lead to new treatment methods to overcome drug resistance. Actually, the reversion of epigenetic changes of DNA and gene transfer skills (gene therapy) has already proved to be effective in reversing PTX resistance. For example, 5-aza-2-deoxycytidine (a demethylation agent) reversed the sensitivity to PTX treatment in breast cancer and ovarian cancer cells $[9,78]$. Exogenous increased levels of p53 significantly improved the sensitivity of PTX providing a basis for gene therapy [22] For another example, the CDK4/6 inhibitor was shown to downregulate p16/cyclin D1/CDK4/(retinoblastoma protein) $\mathrm{Rb}$ signaling pathway and enhance the cytotoxicity of PTX for KRAS mutation-positive lung adenocarcinoma cells [79]. These results encouraged further studies on TSGs associated with PTX resistance in cancers. Moreover, drug resistance was rarely induced by single gene, it was almost caused by two or more genes. For example, tumor suppressor p33 ${ }^{\text {ING1 }}$ markedly increased PTX-induced growth inhibition and apoptosis in TP53wild cells, but not in TP53-mutant cells [76]. Twenty two genes were involved in the regulation of PTX resistance in cancers through certain pathways, particularly through cell cycle and apoptosis (Table 1).

\section{The interaction network of the 22 TSGs}

Bioinformatics analysis has been widely used in nature and life sciences, and it is a feasible and valuable method for gene/protein function prediction. Numerous networks of molecular interactions have made it possible to study gene/protein function using online databases [80]. GeneMANIA is a web-based interface for prediction of gene/protein function on the basis of multiple networks derived from different proteomics and genomic data, and it is fast enough to predict gene/protein function with a significant accuracy rate [81]. The protein interactions of the 22 genes were analyzed using GeneMANIA. The co-localization, co-expression, pathway, shared protein domains and genetic, physical and predictive interactions of the 22 TSGs were shown in Figs. 1, 2, 3, 4, 5, 6, 7 (Genes/proteins are depicted as colored circles and experimentally detected relationships between genes/proteins as connecting lines. Black circles are the 22 TSGs, gray circles are other genes/protein related to the 22 TSGs). In detail, $B R C A 1$ has similar expression level with 


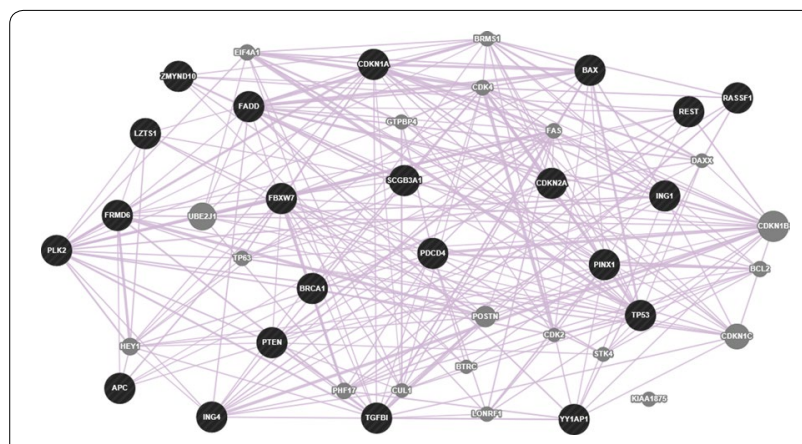

Fig. 1 The co-expression network of the 22 TSGs based on GeneMANIA. Co-expression: two genes are linked if their expression levels are similar across conditions in a gene expression study

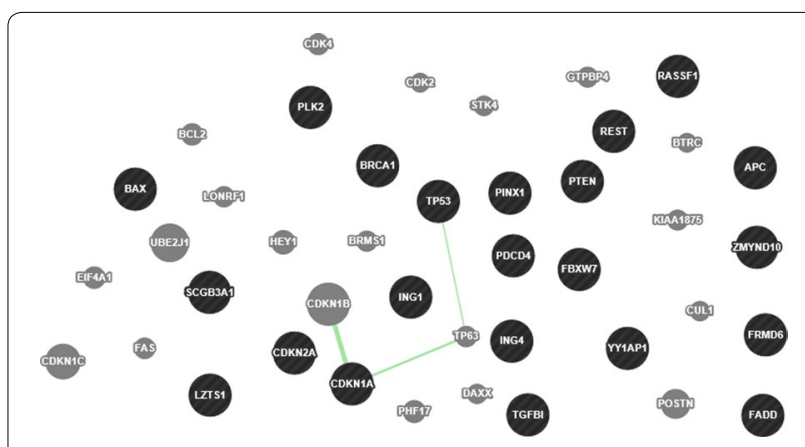

Fig. 4 The genetic interactions network of the 22 TSGs based on GeneMANIA. Genetic interaction: Two genes are functionally associated if the effects of perturbing one gene were found to be modified by perturbations to a second gene

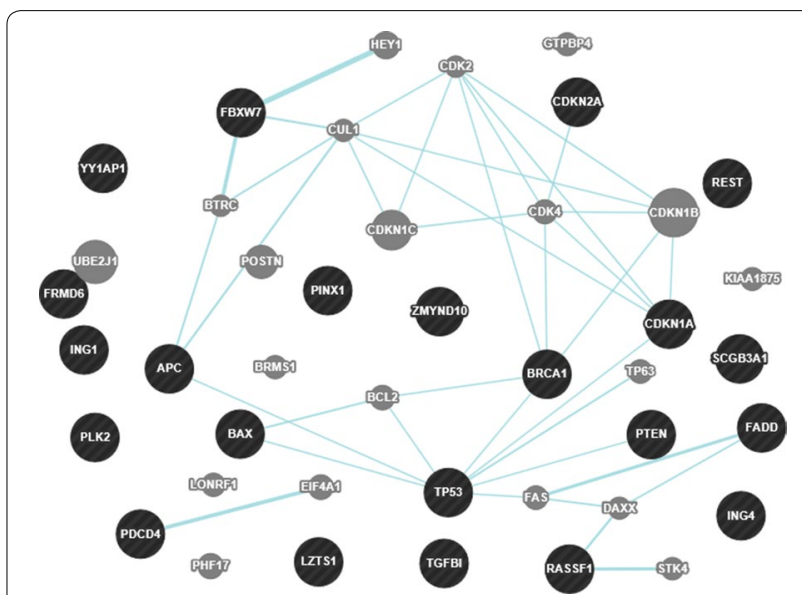

Fig. 5 The pathway network of the 22 TSGs based on GeneMANIA. Pathway: Two gene products are linked if they participate in the same reaction within a pathway

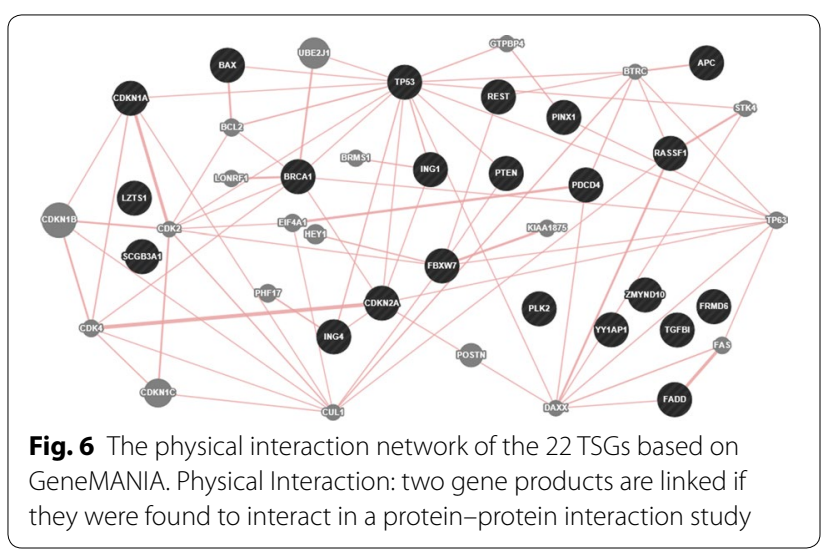

$C D K N 2 A$, participates in the same pathway with TP53, and has physical interactions with CDKN2A and TP53. TP53 has similar expression level with FADD, PDCD4, 


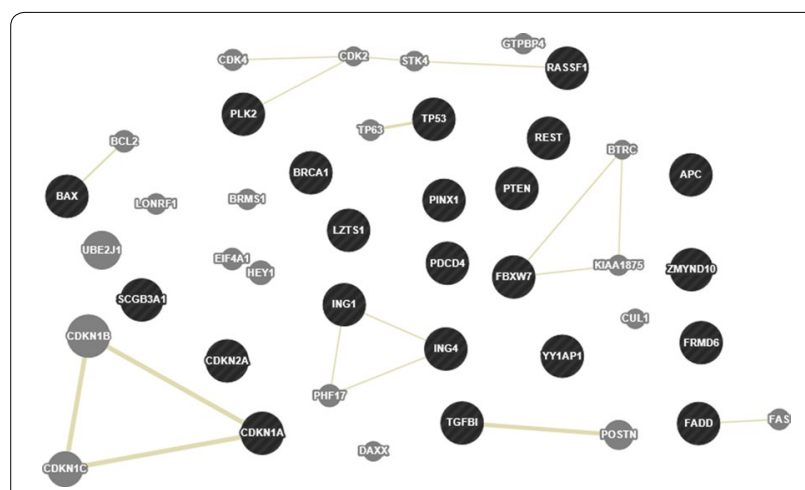

Fig. 7 The shared protein domain network of the 22 TSGs based on GeneMANIA. Shared protein domains: Two gene products are linked if they have the same protein domain

$C D K N 1 A$ and $B a x$, participates in the same pathway with $B R C A 1, A P C, C D K N 1 A, P T E N$ and Bax, and has physical interactions with BRCA1, ING1, CDKN1A, ING4, $B a x$ and $C D K N 2 A$. PTEN has similar expression level with PDCD4, FBW7, TP53, PLK2, APC and TGFBI, participates in the same pathway with TP53, and has physical interactions with TP53, FBW7. APC has co-localization with $F B W 7$ and the similar expression level with $F B W 7$, $h E x, P T E N$ and REST, and participates in the same pathway with TP53. CDKN1A has the similar expression level with TGFBI, ING1, FADD, TP53, CDKN2A and PLK2, and the same protein domain and physical interaction with TP53. CDKN2A has the similar expression level with $C D K N 1 A, C D K N 2 A$, and physical interactions with ING1, $B R C A 1, T P 53, I N G 4 . h E x$ has the similar expression level with FBW7, ING1, RASSF1, PLK2, REST, PDCD4 and TGFBI. RASSF1 has the similar expression level with $B L U, I N G 4$ and TGFBI. YAP has the similar expression level with TGFBI, PinX1, ING1, ING4 and FADD. ING4 has the similar expression level with $Y A P, R A S S F 1, F A D D$, $P D C D 4, B a x$ and $P L K 2$, the same protein domain with ING1 and physical interactions with TP53 and CDKN2A. HIN-1 has the similar expression level with $F A D D$, REST, LZTS1 and BLU. PLK2 has the same protein location with $T G F B I$, and the similar expression level with TGFBI, PTEN, LZTS1, ING4, CDKN1A, ING1, hEx and
FBW7. LZTS1 has the similar expression level with PLK2, $F B W 7$ and $H I N-1$. FBW7 has the same protein location with $A P C$, interacts with REST and PTEN, and has the similar expression level with PLK2, APC, TGFBI, LZTS1, PDCD4, CDKN1A, PTEN, REST and Bax. BLU has the similar expression level with RASSF1, PDCD4, HIN-1 and REST. TGFBI has the similar expression level with FBW7, hEx, Bax, PTEN, CDKN1A, YAP and RASSF1. REST has the similar expression with $B L U, A P C, \operatorname{Pin} X 1$, $F B W 7, F A D D$ and $H I N-1$. FADD has the similar expression of ING1, PinX1, CDKN1A, ING4, HIN-1, REST, YAP, Bax and TP53. PDCD4 has the similar expression with FBW7, TP53, ING4, BLU and PTEN. Bax has the similar expression with ING4, PinX1, TP53, CDKN1A, ING1, $F B W 7, F A D D$ and TGFBI, and participates in the same pathway with TP53. PinX1 has the similar expression level with YAP, REST, Bax and FADD. ING1 shares the same protein domain with ING4 and interacts with TP53 and CDKN2A. The cross-interaction of the 22 TSGs demonstrates that these genes may contribute to PTX resistance as a group.

\section{Annotated molecular functions of the 22 TSGs according to the protein interaction network}

The molecular function of the 22 TSGs may be predicted by using GeneMANIA network. By analysis, there were four summarized functions to be possibly close to chemotherapy resistance (Table 2). The cell cycle-related function covered 12 of the 22 TSGs and additional 10 genes. The cell apoptosis-related function covered eight TSGs and additional seven genes. The protein ubiquitinationrelated function covered six TSGs and additional five genes. The cell growth-related function covered seven TSGs and additional four genes. Since the cell cyclerelated function was annotated with the highest false discovery rate (FDR), the regulation function of TSGs on cell cycle was considered more closely related to chemotherapy resistance than other three pathway functions.

\section{Other related genes in the network}

In the network, 20 other related genes/proteins that mediate the relationship of the 22 TSGs. They have interactions

Table 2 Summarized molecular functions of the 22 TSGs according to the protein interaction network

\begin{tabular}{llll}
\hline Related function & False discovery rate & Number of the 22 TSGs & Other genes \\
\hline Cell cycle & $7.14 \mathrm{e}^{-12} \sim 4.48 \mathrm{e}^{-2}$ & $\begin{array}{c}\text { PLK2, FBW7, TP53, PTEN, APC, BRCA1, CDKN1A, } \\
\text { CDKN2A, ING4, RASSF1, PDCD4, FADD }\end{array}$ & $\begin{array}{c}\text { CUL1, CDK2, CDK4, CDKN1C, CDKN1B, GTPBP4, TP63, } \\
\text { PHF17, BRMS1, STK4 }\end{array}$ \\
Apoptosis & $1.17 \mathrm{e}^{-9} \sim 1.16 \mathrm{e}^{-2}$ & $\begin{array}{c}\text { APC, REST, CDKN2A, FADD, ING4, TP53, BaX, BRCA1 } \\
\text { Protein ubiquitination }\end{array}$ & $\begin{array}{l}\text { BRMS1, TP63, FAS, STK4, CDKN1B, BCL2, CUL1 } \\
\text { Cell growth }\end{array}$ \\
\hline
\end{tabular}


with the 22 candidate genes, and participate in the similar biological process which the 22 genes are involved (Table 2), which indicates that they may be related to PTX or other drug resistance in cancers. Some of them had been studied in drug resistance. For example, tumor protein 63 (TP63), a TP53 family protein, which expressed a variety of isoforms. DeltaNp63alpha belonged to the members of the N-terminally truncated (DeltaN) p63 subfamily, it can trigger anti-apoptotic related pathway result to chemo-resistance in hepatocellular carcinoma [82]. Ovarian cancer cell line with acquired resistance to carboplatin revealed low levels of the gene cyclin-dependent kinase inhibitor $1 \mathrm{C}(C D K N 1 C)$, and demethylation agent can reverse the silencing of $C D K N 1 C$ and increased the apoptotic response to carboplatin [83]. Bcl-2, is specifically considered as an important anti-apoptotic protein and classified as an oncogene, the expression of $\mathrm{Bcl}-2$ can affect PTX induced apoptosis [84]. The $\mathrm{Bcl}-2 / \mathrm{Bax}$ ratio has shown a significant increase in PTX-resistance cancer cells [56, 57]. Hairy/enhancer-of-split related with YRPW motif protein 1 (HEY1), cyclin-dependent kinase inhibitor $1 \mathrm{~B}(C D K N 1 B)$ and fas cell surface death receptor (Fas) acted as a part of signaling pathways involved in drug resistance [85]. Death-associated protein 6 (DAXX) has been shown to regulate PTX-sensitivity in tumor [86]. $C D K 4$ and $C D K 2$ are not only involved in the formation of tumor resistance but also the inhibitors of cyclin-dependent kinase which has been the anti-cancer agent used in clinic [87].

\section{Conclusion}

It is well known that TSGs play an important role in cell cycle, angiogenesis and signal transduction, and currently TSGs are also considered to participate in the formation of chemo-resistance. In this review, we reported an overview of the 22 TSGs associated with PTX resistance in cancer. The status and ways of TSGs to regulate PTX resistance in several types of cancer were integrated in Table 1. Using GeneMANIA, the interaction analysis of TSGs was performed and it was shown that cell cycle might be the main manner for the participation of TSGs in PTX resistance in human cancers, and the 22 TSGs had a direct or indirect relationship with each other and could contribute to PTX resistance as a group.

Therefore, profiling the TSGs status of individual tumors, such as mRNA levels and protein levels, is critical in guiding the optimization of personalized medicines to better sensitize the individual patient to specific drugs. Understanding the mechanistic basis and identification of robust biomarkers could also predict optimal use of chemotherapy in patients. We anticipate that in the future such approaches will benefit clinical development of anticancer therapeutics directly or indirectly targeting TSGs.

\section{Abbreviations}

APC: adenomatous polyposis coli; AKT: protein kinase B; BRCA1: breast cancer 1; BLU: zinc finger MYND domain-containing protein 10; BCL-2: B cell CLL/ lymphoma 2; BTRC: beta-transducin repeat containing E3 ubiquitin protein ligase; BRMS1: breast cancer metastasis suppressor 1; CDK1: cyclin-dependent kinase 1; CDK2: cyclin-dependent kinase 2; CDK4: cyclin-dependent kinase 4; CDK6: cyclin-dependent kinase 6; CDKN2A: cyclin-dependent kinase inhibitor 2A; CDKN1A: cyclin-dependent kinase inhibitor 1A; CDKN1C: cyclin-dependent kinase inhibitor 1C; CDKN1B: cyclin-dependent kinase inhibitor 1B; CKIs: cyclin-dependent kinase inhibitors; CUL1: cullin 1; DAXX: death-associated protein 6; ESCC: esophageal squamous cell carcinoma; FDR: false discovery rate; FBW7: f-box and WD repeat domain containing 7; FADD: phosphorylation of the Fas-associated death domain; FAS: fas cell surface death receptor; GTPBP4: GTP binding protein 4; hEx: human homolog of drosophila expanded; HNSCC: human brain and neck squamous cell carcinoma; HIN-1: high in normal-1; HEY 1: hairy/enhancer-of-split related with YRPW motif protein 1; ING1: inhibitor of growth family member 1; ING4: inhibitor of growth 4; iASPP. inhibitor of apoptosis-stimulating protein of p53; JNK: c-Jun N-terminal kinase; LZTS1: leucine zipper putative tumor suppressor 1; mir-22: microRNA 22; mir-135a: microRNA 135a; MDR: multiple drug resistance; MMTV-PyMT: mouse mammary tumor virus promoter-polyoma middle T-antigen; MAPK: mitogenactivated protein kinase; NSCLC: non-small-cell carcinoma; PTX: paclitaxel; PTEN: phosphatase and tensin homolog; PinX1: the telomere/telomerase binding factor; PDCD4: programmed cell death protein 4; PI3 k: phosphatidylinositol 3-kinase; PLK2: polo-like kinase 2; PIP3: phosphatidylinositol(3,4,5)trisphosphate; PUMA: p53 upregulated modulator of apoptosis; PHF17: PHD finger protein 17; Rb: retinoblastoma; REST: RE1-silencing transcription factor; RASSF1: ras association domain-containing protein 1; SAPK: stressactivated protein kinase; siRNA: small interfering RNA; STK4: serine/threonine kinase 4; TP53: tumor protein 53; TP63: tumor protein 63; TGFBI: transforming growth factor- $\beta$-induced; TSGs: tumor suppressor genes; TAZ: transcriptional co-activator with PDZ-binding motif; TUBB3: tubulin beta 3 class III; YAP: yesassociated protein.

\section{Authors' contributions}

$J H X$ conceived the idea, did literature search and drafted the manuscript; SLH did literature search and contributed in drafting the manuscript; GS and GDS supervised the project, made substantial contributions to the concept and design of manuscript, and drafted the manuscript. All authors read and approved the final manuscript.

\section{Author details}

${ }^{1}$ Department of Geriatrics, Anhui Provincial Hospital affiliated to Anhui Medical University, 17 Lujiang Road, Hefei 230001, China. ${ }^{2}$ Anhui Provincial Key Laboratory of Tumor Immunotherapy and Nutrition Therapy, Hefei 230001, China.

\section{Acknowledgements}

The work was funded by the Anhui Provincial Natural Science Foundation (Grant number 1408085MH167) and Anhui Provincial science and technology key project (Grant number 1301042094) and was also supported by the Anhui Provincial Program for Industry Innovative Research Team of Cancer Immunotherapy and Nutrition Diagnosis and Therapy.

\section{Competing interests}

The authors declare that they have no competing interests.

Received: 31 March 2015 Accepted: 12 February 2016

Published online: 20 February 2016

\section{References}

1. Balighi K, Daneshpazhooh M, Aghazadeh N, Hejazi P, Aryanian Z, Azizpour A, et al. Pemphigus vulgaris-associated Kaposi's sarcoma: response to paclitaxel and review of the literature. Eur Acad Dermatol Venereol. 2014;28(8):987-94.

2. Tauchi Y, Kashiwagi S, Ishihara S, Asano Y, Sakimura C, Kurata K, et al. Clinical experience of nab-Paclitaxel treatment in 31 patients with breast cancer. Gan to kagaku ryoho. 2014;41(12):1948-50. 
3. Robinson WR, Davis N, Rogers AS. Paclitaxel maintenance chemotherapy following intraperitoneal chemotherapy for ovarian cancer. Int J Gynecol Cancer. 2008;18(5):891-5.

4. Horinouchi $\mathrm{H}$, Yamamoto $\mathrm{N}$, Nokihara H, Horai T, Nishio M, Ohyanagi $\mathrm{F}$, et al. A phase 1 study of linifanib in combination with carboplatin/paclitaxel as first-line treatment of Japanese patients with advanced or metastatic non-small cell lung cancer (NSCLC). Cancer Chemother Pharmacol. 2014;74(1):37-43.

5. Jimenez B, Trigo JM, Pajares BI, Saez MI, Quero C, Navarro V, et al. Efficacy and safety of weekly paclitaxel combined with cetuximab in the treatment of pretreated recurrent/metastatic head and neck cancer patients. Oral Oncol. 2013;49(2):182-5.

6. Gornstein E, Schwarz TL. The paradox of paclitaxel neurotoxicity: mechanisms and unanswered questions. Neuropharmacology. 2014;76:175-83.

7. Stordal B, Davey R. A systematic review of genes involved in the inverse resistance relationship between cisplatin and paclitaxel chemotherapy: role of BRCA1. Curr Cancer Drug Targets. 2009;9(3):354-65.

8. Visser-Grieve S, Hao Y, Yang X. Human homolog of drosophila expanded, hEx, functions as a putative tumor suppressor in human cancer cell lines independently of the Hippo pathway. Oncogene. 2012;31(9):1189-95.

9. Ho CM, Huang CJ, Huang CY, Wu YY, Chang SF, Cheng WF. Promoter methylation status of $\mathrm{HIN}-1$ associated with outcomes of ovarian clear cell adenocarcinoma. Mol Cancer. 2012;11:53.

10. Sherr CJ. Principles of tumor suppression. Cell. 2004;116(2):235-46.

11. Narod SA, Foulkes WD. BRCA1 and BRCA2: 1994 and beyond. Nat Rev Cancer. 2004:4(9):665-76.

12. Tassone P, Tagliaferri P, Perricelli A, Blotta S, Quaresima B, Martelli ML, et al. BRCA1 expression modulates chemosensitivity of BRCA1-defective HCC1937 human breast cancer cells. Br J Cancer. 2003;88(8):1285-91.

13. Quinn JE, James CR, Stewart GE, Mulligan JM, White P, Chang GK, et al. BRCA1 mRNA expression levels predict for overall survival in ovarian cancer after chemotherapy. Clin Cancer Res. 2007;13(24):7413-20.

14. Saiki Y, Ogawa T, Shiga K, Sunamura M, Kobayashi T, Horii A. A human head and neck squamous cell carcinoma cell line with acquired cisdiamminedichloroplatinum-resistance shows remarkable upregulation of brca1 and hypersensitivity to taxane. Int J Otolaryngol. 2011;2011:521852.

15. Chabalier C, Lamare C, Racca C, Privat M, Valette A, Larminat F. BRCA downregulation leads to premature inactivation of spindle checkpoint and confers paclitaxel resistance. Cell Cycle. 2006;5(9):1001-7.

16. Sung M, Giannakakou P. BRCA1 regulates microtubule dynamics and taxane-induced apoptotic cell signaling. Oncogene. 2014;33(11):1418-28.

17. Gilmore PM, McCabe N, Quinn JE, Kennedy RD, Gorski JJ, Andrews HN, et al. BRCA1 interacts with and is required for paclitaxel-induced activation of mitogen-activated protein kinase kinase kinase 3. Cancer Res. 2004;64(12):4148-54.

18. Meek DW. Regulation of the p53 response and its relationship to cancer. Biochem J. 2015;469(3):325-46.

19. Vogt U, Zaczek A, Klinke F, Granetzny A, Bielawski K, Falkiewicz B. p53 gene status in relation to ex vivo chemosensitivity of non-small cell lung cancer. J Cancer Res Clin Oncol. 2002;128(3):141-7.

20. Kandioler D, Stamatis G, Eberhardt W, Kappel S, Zochbauer-Muller S, Kuhrer l, et al. Growing clinical evidence for the interaction of the p53 genotype and response to induction chemotherapy in advanced nonsmall cell lung cancer. J Thorac Cardiovasc Surg. 2008;135(5):1036-41.

21. Lu C, El-Deiry WS. Targeting p53 for enhanced radio- and chemo-sensitivity. Apoptosis. 2009;14(4):597-606.

22. Guntur VP, Waldrep JC, Guo JJ, Selting K, Dhand R. Increasing TP53 protein sensitizes non-small cell lung cancer to paclitaxel and cisplatin in vitro. Anticancer Res. 2010;30(9):3557-64.

23. Yu J, Yue W, Wu B, Zhang L. PUMA sensitizes lung cancer cells to chemotherapeutic agents and irradiation. Clin Cancer Res. 2006;12(9):2928-36.

24. Liu Q, Sui R, Li R, Miao J, Liu J. Biological characteristics of taxol-resistant ovarian cancer cells and reversal of taxol resistance by adenovirus expressing TP53. Mol Med Rep. 2015;11(2):1292-7.

25. Dean M, Fojo T, Bates S. Tumor stem cells and drug resistance. Nat Rev Cancer. 2005:5(4):275-84

26. Seagle BL, Yang CP, Eng KH, Dandapani M, Odunsi-Akanji O, Goldberg GL, et al. TP53 hot spot mutations in ovarian cancer: selective resistance to microtubule stabilizers in vitro and differential survival outcomes from The Cancer Genome Atlas. Gynecol Oncol. 2015;138(1):159-64.
27. Jiang L, Siu MK, Wong OG, Tam KF, Lu X, Lam EW, et al. iASPP and chemoresistance in ovarian cancers: effects on paclitaxel-mediated mitotic catastrophe. Clin Cancer Res. 2011;17(21):6924-33.

28. Yang YC, Hsu YT, Wu CC, Chen HT, Chang MS. Silencing of astrin induces the p53-dependent apoptosis by suppression of HPV18 E6 expression and sensitizes cells to paclitaxel treatment in HeLa cells. Biochem Biophys Res Commun. 2006;343(2):428-34.

29. Cully M, You H, Levine AJ, MakTW. Beyond PTEN mutations: the PI3K pathway as an integrator of multiple inputs during tumorigenesis. Nat Rev Cancer. 2006;6(3):184-92.

30. Wu H, Wang K, Liu W, Hao Q. PTEN overexpression improves cisplatinresistance of human ovarian cancer cells through upregulating KRT10 expression. Biochem Biophys Res Commun. 2014:444(2):141-6.

31. Esteva FJ, Guo H, Zhang S, Santa-Maria C, Stone S, Lanchbury JS, et al. PTEN, PIK3CA, p-AKT, and p-p70S6 K status: association with trastuzumab response and survival in patients with HER2-positive metastatic breast cancer. Am J Pathol. 2010;177(4):1647-56.

32. Chen L, Li WF, Wang HX, Zhao HN, Tang JJ, Wu CJ, et al. Curcumin cytotoxicity is enhanced by PTEN disruption in colorectal cancer cells. World J Gastroenterol. 2013;19(40):6814-24.

33. Cassinelli G, Zuco V, Gatti L, Lanzi C, Zaffaroni N, Colombo D, et al. Targeting the Akt kinase to modulate survival, invasiveness and drug resistance of cancer cells. Curr Med Chem. 2013;20(15):1923-45.

34. Ou Y, Ma L, Ma L, Huang Z, Zhou W, Zhao C, et al. Overexpression of cyclin B1 antagonizes chemotherapeutic-induced apoptosis through PTEN/Akt pathway in human esophageal squamous cell carcinoma cells. Cancer Biol Ther. 2013;14(1):45-55.

35. Li J, Zhang Y, Zhao J, Kong F, Chen Y. Overexpression of miR-22 reverses paclitaxel-induced chemoresistance through activation of PTEN signaling in p53-mutated colon cancer cells. Mol Cell Biochem. 2011;357(1-2):31-8.

36. Davies AE, Kortright $K$, Kaplan KB. Adenomatous polyposis coli mutants dominantly activate Hsf1-dependent cell stress pathways through inhibition of microtubule dynamics. Oncotarget. 2015;6(28):25202-16.

37. Lesko AC, Goss KH, Prosperi JR. Exploiting APC function as a novel cancer therapy. Curr Drug Targets. 2014;15(1):90-102.

38. VanKlompenberg MK, Bedalov CO, Soto KF, Prosperi JR. APC selectively mediates response to chemotherapeutic agents in breast cancer. BMC Cancer. 2015;15:457.

39. Nagel R, le Sage C, Diosdado B, van der Waal M, Oude Vrielink JA, Bolijn A, et al. Regulation of the adenomatous polyposis coli gene by the miR-135 family in colorectal cancer. Cancer Res. 2008;68(14):5795-802.

40. Holleman A, Chung I, Olsen RR, Kwak B, Mizokami A, Saijo N, et al. miR135 a contributes to paclitaxel resistance in tumor cells both in vitro and in vivo. Oncogene. 2011;30(43):4386-98.

41. Ling Y, Zhong Y, Perez-Soler R. Disruption of cell adhesion and caspasemediated proteolysis of beta- and gamma-catenins and APC protein in paclitaxel-induced apoptosis. Mol Pharmacol. 2001;59(3):593-603.

42. Ling $\mathrm{YH}$, Consoli U, Tornos C, Andreeff M, Perez-Soler R. Accumulation of cyclin B1, activation of cyclin B1-dependent kinase and induction of programmed cell death in human epidermoid carcinoma KB cells treated with taxol. Int J Cancer. 1998;75(6):925-32.

43. Malumbres M, Barbacid M. Mammalian cyclin-dependent kinases. Trends Biochem Sci. 2005;30:630-41.

44. Murray AW. Recycling the cell cycle: cyclins revisited. Cell. 2004;116(2):221-34

45. Sherr CJ, Roberts JM. CDK inhibitors: positive and negative regulators of G1-phase progression. Genes Dev. 1999;13(12):1501-12.

46. Gillis LD, Leidal AM, Hill R, Lee PW. p21Cip1/WAF1 mediates cyclin B1 degradation in response to DNA damage. Cell Cycle. 2009;8(2):253-6.

47. Li W, Fan J, Banerjee D, Bertino JR. Overexpression of p21 (waf1) decreases G2-M arrest and apoptosis induced by paclitaxel in human sarcoma cells lacking both p53 and functional Rb protein. Mol Pharmacol. 1999;55(6):1088-93.

48. Jang GH, Kim NY, Lee M. Low inducible expression of p21Cip1 confers resistance to paclitaxel in BRAF mutant melanoma cells with acquired resistance to BRAF inhibitor. Mole Cell Biochem. 2015;406(1-2):53-62.

49. Arima Y, Hayashi N, Hayashi H, Sasaki M, Kai K, Sugihara E, et al. Loss of p16 expression is associated with the stem cell characteristics of surface markers and therapeutic resistance in estrogen receptor-negative breast cancer. Int J Cancer. 2012;130(11):2568-79. 
50. Zhao B, Tumaneng K, Guan KL. The Hippo pathway in organ size control, tissue regeneration and stem cell self-renewal. Nat Cell Biol. 2011;13(8):877-83.

51. Badouel $\mathrm{C}, \mathrm{McNeill} H$. Snapshot: the hippo signaling pathway. Cell. 2011;145(3):484

52. Bhagat R, Chadaga S, Premalata CS, Ramesh G, Ramesh C, Pallavi VR, et al. Aberrant promoter methylation of the RASSF1A and APC genes in epithelial ovarian carcinoma development. Cell Oncol. 2012;35(6):473-9

53. Kassler S, Donninger $\mathrm{H}$, Birrer MJ, Clark GJ. RASSF1A and the taxol response in ovarian cancer. Mol Biol Int. 2012;2012:263267.

54. Basu S, Totty NF, Irwin MS, Sudol M, Downward J. Akt phosphorylates the Yes-associated protein, YAP, to induce interaction with 14-3-3 and attenuation of p73-mediated apoptosis. Mol Cell. 2003;11(1):11-23.

55. Yuan M, Tomlinson V, Lara R, Holliday D, Chelala C, Harada T, et al. Yesassociated protein (YAP) functions as a tumor suppressor in breast. Cell Death Differ. 2008;15(11):1752-9.

56. Wang R, Huang J, Feng B, De W, Chen L. Identification of ING4 (inhibitor of growth 4) as a modulator of docetaxel sensitivity in human lung adenocarcinoma. Mol Med. 2012;18:874-86.

57. Sharifi S, Barar J, Hejazi MS, Samadi N. Roles of the Bcl-2/Bax ratio, caspase-8 and 9 in resistance of breast cancer cells to paclitaxel. Asian Pac J Cancer Prev. 2014;15(20):8617-22.

58. Syed N, Coley HM, Sehouli J, Koensgen D, Mustea A, Szlosarek P, et al. Polo-like kinase Plk2 is an epigenetic determinant of chemosensitivity and clinical outcomes in ovarian cancer. Cancer Res. 2011;71(9):3317-27.

59. Califano D, Pignata S, Pisano C, Greggi S, Laurelli G, Losito NS, et al. FEZ1/LZTS1 protein expression in ovarian cancer. J Cell Physiol. 2010;222(2):382-6.

60. Lovat F, Ishii H, Schiappacassi M, Fassan M, Barbareschi M, Galligioni E, et al. LZTS1 downregulation confers paclitaxel resistance and is associated with worse prognosis in breast cancer. Oncotarget. 2014;5(4):970-7.

61. Vecchione A, Baldassarre G, Ishii H, Nicoloso MS, Belletti B, Petrocca F, et al. Fez1/Lzts1 absence impairs Cdk1/Cdc25C interaction during mitosis and predisposes mice to cancer development. Cancer Cell. 2007:11(3):275-89.

62. Wertz IE, Kusam S, Lam C, Okamoto T, Sandoval W, Anderson DJ, et al. Sensitivity to antitubulin chemotherapeutics is regulated by MCL1 and FBW7. Nature. 2011;471(7336):110-4.

63. Chiang YC, Chang MC, Chen PJ, Wu MM, Hsieh CY, Cheng WF, et al. Epigenetic silencing of BLU through interfering apoptosis results in chemoresistance and poor prognosis of ovarian serous carcinoma patients. Endocr Relat Cancer. 2013;20(2):213-27.

64. Park ST, Byun HJ, Kim BR, Dong SM, Park SH, Jang PR, et al. Tumor suppressor BLU promotes paclitaxel antitumor activity by inducing apoptosis through the down-regulation of $\mathrm{BCl}-2$ expression in tumorigenesis. Biochem Biophys Res Commun. 2013;435(1):153-9.

65. Zhao Y, El-Gabry M, Hei TK. Loss of Betaig-h3 protein is frequent in primary lung carcinoma and related to tumorigenic phenotype in lung cancer cells. Mol Carcinog. 2006:45(2):84-92.

66. Irigoyen M, Pajares MJ, Agorreta J, Ponz-Sarvise M, Salvo E, Lozano MD et al. TGFBI expression is associated with a better response to chemotherapy in NSCLC. Mol Cancer. 2010;9:130.

67. Tumbarello DA, Temple J, Brenton JD. B3 integrin modulates transforming growth factor beta induced (TGFBI) function and paclitaxel response in ovarian cancer cells. Mol Cancer. 2012:11:36.

68. Kreisler A, Strissel PL, Strick R, Neumann SB, Schumacher U, Becker CM. Regulation of the NRSF/REST gene by methylation and CREB affects the cellular phenotype of small-cell lung cancer. Oncogene. 2010;29(43):5828-38.

69. Levallet G, Bergot E, Antoine M, Creveuil C, Santos AO, Beau-Faller M et al. High TUBB3 expression, an independent prognostic marker in patients with early non-small cell lung cancer treated by preoperative chemotherapy, is regulated by K-Ras signaling pathway. Mol Cancer Ther. 2012;11(5):1203-13.
70. Gao S, Zhao X, Lin B, Hu Z, Yan L, Gao J. Clinical implications of REST and TUBB3 in ovarian cancer and its relationship to paclitaxel resistance. Tumour Biol. 2012;33(5):1759-65.

71. Jang MS, Lee SJ, Kim CJ, Lee CW, Kim E. Phosphorylation by polo-like kinase 1 induces the tumor-suppressing activity of FADD. Oncogene. 2011;30(4):471-81.

72. Shimada K, Matsuyoshi S, Nakamura M, Ishida E, Kishi M, Konishi N. Phosphorylation of FADD is critical for sensitivity to anticancer drug-induced apoptosis. Carcinogenesis. 2004;25(7):1089-97.

73. Jang MS, Lee SJ, Kang NS, Kim E. Cooperative phosphorylation of FADD by Aur-A and PIk1 in response to taxol triggers both apoptotic and necrotic cell death. Cancer Res. 2011;71(23):7207-15.

74. Wang YQ, Guo RD, Guo RM, Sheng W, Yin LR. MicroRNA-182 promotes cell growth, invasion, and chemoresistance by targeting programmed cell death 4 (PDCD4) in human ovarian carcinomas. J Cell Biochem. 2013;114(7):1464-73.

75. Xu H, Dephoure N, Sun H, Zhang H, Fan F, Liu J, et al. Proteomic profiling of paclitaxel treated cells identifies a novel mechanism of drug resistance mediated by PDCD4. J Proteome Res. 2015;14(6):2480-91.

76. Zhu JJ, Li FB, Zhou JM, Liu ZC, Zhu XF, Liao WM. The tumor suppressor p33ING1b enhances taxol-induced apoptosis by p53-dependent pathway in human osteosarcoma U2OS cells. Cancer Biol Ther. 2005;4(1):39-47

77. Tian XP, Qian D, He LR, Huang H, Mai SJ, Li CP, et al. The telomere/telomerase binding factor $\mathrm{Pin} X 1$ regulates paclitaxel sensitivity depending on spindle assembly checkpoint in human cervical squamous cell carcinomas. Cancer Lett. 2014;353(1):104-14.

78. Mirza S, Sharma G, Pandya P, Ralhan R. Demethylating agent 5-aza-2-deoxycytidine enhances susceptibility of breast cancer cells to anticancer agents. Mol Cell Biochem. 2010;342(1-2):101-9.

79. Zhang XH, Cheng Y, Shin JY, Kim JO, Oh JE, Kang JH. A CDK4/6 inhibitor enhances cytotoxicity of paclitaxel in lung adenocarcinoma cells harboring mutant KRAS as well as wild-type KRAS. Cancer Biol Ther. 2013;14(7):597-605.

80. Yu D, Kim M, Xiao G, Hwang TH. Review of biological network data and its applications. Genom Inform. 2013;11(4):200-10.

81. Warde-Farley D, Donaldson SL, Comes O, Zuberi K, Badrawi R, Chao P, et al. The GeneMANIA prediction server: biological network integration for gene prioritization and predicting gene function. Nucleic Acids Res. 2010;38:W214-20 (Web Server issue).

82. Mundt HM, Stremmel W, Melino G, Krammer PH, Schilling T, Muller M. Dominant negative (Deltan) p63alpha induces drug resistance in hepatocellular carcinoma by interference with apoptosis signaling pathways. Biochem Biophys Res Commun. 2010;396(2):335-41.

83. Coley HM, Safuwan NA, Chivers P, Papacharalbous E, Giannopoulos T, Butler-Manuel S, et al. The cyclin-dependent kinase inhibitor p57(Kip2) is epigenetically regulated in carboplatin resistance and results in collateral sensitivity to the CDK inhibitor seliciclib in ovarian cancer. Br J Cancer. 2012;106(3):482-9.

84. Chatterjee A, Chattopadhyay D, Chakrabarti G. MiR-16 targets BCl-2 in paclitaxel-resistant lung cancer cells and overexpression of miR-16 along with miR-17 causes unprecedented sensitivity by simultaneously modulating autophagy and apoptosis. Cell Signal. 2015;27(2):189-203.

85. Liu H, Peng J, Bai Y, Guo L. Up-regulation of DLL1 may promote the chemotherapeutic sensitivity in small cell lung cancer. Zhongguo Fei Ai Za Zhi. 2013;16(6):282-8.

86. Giovinazzi S, Morozov VM, Summers MK, Reinhold WC, Ishov AM. USP7 and Daxx regulate mitosis progression and taxane sensitivity by affecting stability of aurora-A kinase. Cell Death Differ. 2013;20(5):721-31.

87. Hosford SR, Miller TW. Clinical potential of novel therapeutic targets in breast cancer: CDK4/6, Src, JAK/STAT, PARP, HDAC, and PI3K/AKT/mTOR pathways. Pharmgenom Pers Med. 2014;7:203-15. 